\title{
PROGRAMA SAÚDE DAFAMÍLIA: A OPINIÃO DA COMUNIDADE
}

\author{
A FAMILY HEALTH PROGRAM: COMMUNITY'S ACCOUTS ABOUT THE PROGRAM \\ PROGRAM SALUD DE LA FAMÍLIA: LA PERCEPCIÓN DE COMUNIDAD
}

Eliany Nazaré Oliveira*

\begin{abstract}
RESUMO: Estudo exploratório descritivo, realizado no Município de Sobral, localizado a $230 \mathrm{~km}$ de Fortaleza Ceará. 0 período de coleta de dados foi de abril a junho de 1999. Tivemos como objetivo, descrever a percepção das famílias/comunidade sobre a atuação do Programa Saúde da Família nesta cidade. Foram escolhidas 13 unidades de saúde da zona urbana. Nesses bairros foram entrevistadas 123 famílias. Através de visitas domiciliares, 43 estudantes do primeiro período do Curso de Enfermagem abordaram 123 famílias. Os resultados mostram que $100 \%$ das famílias conhecem e utilizam os serviços do PSF, $73 \%$ das famílias tiveram seus problemas solucionados pelas equipes, $68 \%$ referem que melhorou 0 acesso aos serviços de saúde. Quanto às opiniões sobre o que deve melhorar, a maioria das famílias ainda deseja um atendimento respaldado na área curativa, isso retrata que perspectivas de melhora dos serviços são calcadas no modelo assistencial que imperou por muitos anos.
\end{abstract}

PALAVRAS CHAVE: Saúde da Família; Planos e programas de saúde; Avaliação; Desenvolvimento da comunidade.

\section{INTRODUÇÃO}

Nas últimas décadas, a crise estrutural do setor público é claramente percebida, principalmente por afetar a oferta dos serviços públicos, com destaque para os serviços públicos de saúde que foram profundamente atingidos.

Durante a VIII Conferência Nacional de Saúde, cujas repercussões culminaram na redação do artigo 196 da Constituição de 1988, e que trata da efetiva consolidação do Sistema Único de Saúde (SUS), surgindo com o intuito de superação da crise na saúde, estabeleceu-se um dos marcos para o resgate da saúde dos brasileiros.

Em vista da necessidade do estabelecimento de mecanismos capazes de assegurar a continuidade dessas conquistas sociais, várias propostas de mudanças - inspiradas pela Reforma Sanitária e pelos princípios do SUS, têm sido esboçadas ao longo do tempo, trazidas, entre outras, nos projetos de criação dos distritos sanitários e dos sistemas locais de saúde. Essas iniciativas, entretanto, apresentam avanços e retrocessos e seus resultados têm sido pouco perceptíveis na estrutura dos serviços de saúde, exatamente por não promover mudanças significativas no modelo assistencial (Ministério da Saúde, 1998).

Um novo modelo faz-se necessário para reverter tal situação, desde que voltado para uma nova ética setorial, rompendo com os tradicionais alicerces das atuais organizações de prestação de serviços, tendo como base os princípios da universalidade, equidade e integridade, trabalhando com a saúde de forma ampla e compartilhada por todos - governo, profissionais e sociedade.

O Programa S aúde da Família (PSF) vem atender às diretrizes e ao ideário deste novo modelo, apontando para a valorização de tudo o que interage com o indivíduo, ao contexto de sua existência e às relações familiares e sociais que tão intensamente marcam sua realidade sanitária. Este novo modelo deve trazer modificações na prática assistencial, calcadas na mudança das relações entre o profissional e o usuário. 0 indivíduo e a família passam, então, a ser objeto de trabalho desses profissionais e, por conseguinte, a comunidade. Para tal papel, emerge um novo ator social, que deixa de ser usuário de um serviço e passa a ser sujeito do processo, parceiro e co-responsável por tais serviços e pelo pleno e apropriado funcionamento deste (Ministério da Saúde, 1999).

* Enfermeira, Mestra em Enfermagem Saúde Comunitária e P rofessora Auxiliar da Universidade Estadual Vale do Acaraú - UVA. e mail - elianynazare@ bol.com.br 
O PSF surgiu como um dos caminhos para reverter um modelo até então excludente e verticalizado, em que a doença era prioridade e a assistência e os recursos dirigiam-se para a área hospitalar. 0 indivíduo era concebido em partes, fragmentado, o doente e a doença eram o objeto do cuidado.

No Ceará a descentralização progrediu rapidamente nos últimos anos. 0 gerenciamento dos serviços está, atualmente, na grande maioria, sob a responsabilidade dos municípios. Desde a implantação do PSF pelo Ministério da Saúde em 1994, um extenso projeto para construção de um modelo direcionado à promoção da saúde vem sendo adotado e expandido em todo o território nacional. A Secretaria Estadual de Saúde (SESA) adota o PSF como estratégia central de atuação, assumindo-o como mecanismo de transformação do atual padrão assistencial e promovendo uma cooperação com as secretarias municipais. No Ceará, 125 municípios aderiram à proposta do PSF e 615 equipes já estão cadastradas em todo o Estado.

Entre esses municípios temos, Sobral, localizado a $230 \mathrm{Km}$ da capital, concentrando uma população de 147.000 habitantes, onde a maioria, $87 \%$, vivem na zona urbana. Atualmente conta com 31 equipes de Saúde da Família, composta cada uma de: agente de saúde; auxiliar de enfermagem; e dependendo da necessidade agrega dois a três enfermeiros e um a dois médicos, totalizando mais de 70 profissionais de nível superior. No momento, cobre aproximadamente $100 \%$ da população sobralense.

S egundo Dominguez (1998), o PSF é um modelo de assistência que desenvolve ações de prevenção e promoção à saúde do indivíduo, da família e da comunidade. Constitui a estratégia fundamental no nível de atenção primária, que é o pilar mais importante do SUS. Serra (2000) lembra que o modelo do PSF já é hegemônico na configuração do sistema de atenção básica à saúde no Brasil, desenha-se ainda, em um futuro próximo, como uma estratégia de mudança radical da forma de se fazer saúde no Brasil. Uma transformação desta monta, que enfrenta adversários históricos e interesses fortemente articulados, precisa mais do que bons propósitos: necessita de resultados. Portanto, avaliar as políticas públicas implementadas em nosso país, e monitorar o impacto desta sobre a população é um dever de todo cidadão.

Para Miranda (1998), o PSF é uma opção política explícita do governo federal, que impõe aos municípios brasileiros sua adoção, a qual muitas vezes leva à busca indiscriminada de recursos financeiros. 0 autor lembra que devemos ficar atentos, pois inúmeras e distintas iniciativas de organização da rede básica de serviços de saúde ao nível municipal passarão doravante a autodenominar "Programa de Saúde da Família" para poderem receber o referido repasse de recursos ( NOB/96 - Plano Assistencial Básico - PAB). Com isso, podemos ter mais um faz-de-conta do que propriamente serviços efetivos e resolutivos, não se constituindo em uma nova forma de atenção à saúde guiado pelos princípios da construção do SUS. Em contrapartida, 0 Ministro da Saúde afirma que o PSF não tem mais o charme de ser alternativo, o viés ousado de se colocar como possibilidade, a ambientação institucional de um programa isolado na lógica mais ampla do sistema de saúde. Ele provou que funciona, e por isso mesmo tem que funcionar cada vez melhor. E para todos.

A meta do governo federal é implantar 20 mil equipes até o ano 2002, com 150 mil agentes comunitários de saúde, acompanhando cerca de 80 milhões de pessoas. 0 Ministério da Saúde elegeu o Programa Agente Comunitário de Saúde e o PSF como estratégias para a organização da atenção básica no País. Consideramos uma meta arrojada, mas acreditamos que o sistema de saúde vive, se não o momento político mais importante de sua história, pelo menos o mais decisivo.

Mediante a contextualização inicial, destacamos a importância da avaliação sistemática e processual da experiência do PSF, não só em Sobral como também em todo País, pois através deste importante instrumento de monitoramento, teremos subsídios necessários para identificação de problemas, planejamento de ações, reorganização de serviços e implantação de um prática consciente.

Fomos para o campo com o seguinte objetivo: perceber a opinião das famílias/comunidade sobre a atuação do PSF em algumas unidades do Município de Sobral.

\section{METODOLOGIA}

Trata-se de um estudo exploratório descritivo. Foi realizado no Município de Sobral, no período de abril a junho de 1999, durante o estágio de campo de alunos do Curso de Enfermagem que participavam da disciplina de Introdução à Enfermagem. 
A cidade foi municipalizada em 1997, atualmente apresenta gestão plena, com 31 equipes do PSF, abrangendo aproximadamente $100 \%$ da população sobralense. Na zona urbana, atuam 22 equipes, das quais foram escolhidas 13 unidades de saúde: Sumaré, Alto Novo, Padre Palhano, Alto da Brasília, Sinhá Sabóia, Expectativa, Dom Expedito, Vila União, Terrenos Novos, Pedrinhas, J unco, Tamarindo e Santa Casa. A escolha se deu por sorteio, e a opção pela zona urbana se justifica pela facilidade de acesso aos estudantes, já que a Universidade Estadual Vale do Acaraú - UVA encontra-se instalada também na zona urbana.

Para a coleta das informações, foi utilizado um formulário com 20 perguntas ( abertas e fechadas), composto pelos seguintes dados: identificação, situação hidrossanitária e socioeconômica, questionamentos sobre a atuação do PSF dos bairros em questão.

Os procedimentos de coleta de dados foram viabilizados pela atividade de campo dos alunos do Curso de Enfermagem da Universidade Estadual Vale do Acaraú - UVA. As entrevistas foram realizadas por 43 alunos da disciplina Introdução à Enfermagem, e teve o objetivo de inserir 0 acadêmico nas unidades de atenção básica, propiciando o conhecimento das ações do PSF, além, é claro, de oferecer instrumentos para identificação da opinião da população sobre o programa.

Inicialmente contatamos a equipe, informando sobre a presença dos alunos nas unidades e o dia estabelecido para tal. As atividades se desenvolveram em duas etapas, sendo a primeira na própria unidade para identificação e conhecimento de todo trabalho da equipe. Na outra fase, os alunos dirigiram-se às famílias, através de visitas domiciliares. Neste seguimento do trabalho, cada aluno fez três visitas com aplicação do formulário, totalizando 129 famílias entrevistadas. Dos formulários aplicados, 9 foram excluídos por estarem incompletos. Desta forma, a amostra foi constituída por 123 famílias. Vale lembrar, que em momento anterior, todos os estudantes foram orientados sobre como abordar as famílias. Também foi exigido que as famílias escolhidas deveriam morar a uma distância de duas a três quadras da unidade de saúde.

Quanto aos aspectos éticos da pesquisa, tivemos como base a portaria 196/96 do Conselho Nacional de Saúde. Todas as famílias foram informadas do objetivo da pesquisa, e tiveram direito de optar em responder ou não ao formulário. A partir do consentimento livre e esclarecido das famílias, que se caracterizou apenas verbalmente, iniciamos a aplicação do formulário. Garantimos o anonimato e o respeito aos valores culturais, sociais, morais, religiosos, bem como hábitos e costumes, já que necessitávamos penetrar nas casas e permanecer por alguns minutos. Quanto ao retorno dos benefícios obtidos através da pesquisa para as famílias, acreditamos que as dificuldades e deficiências detectadas no trabalho serão um instrumento para que os gestores reorganizem as ações de saúde no município, onde cada família será beneficiada com um serviço de melhor qualidade (Brasil, 2000).

\section{RESULTADOS E COMENTÁRIOS}

\section{ALGUMAS CARACTERÍSTICAS DO MUNICÍPIO}

Sobral localiza-se na região norte do Estado do Ceará, a 230 km de Fortaleza. Conta com uma população de 147.000 habitantes, sendo a quinta maior população do Estado. Compõe-se de $52 \%$ de pessoas do sexo feminino e $48 \%$ do sexo masculino. Deste total, $14 \%$ são menores de 5 anos de idade. Chama a atenção o fato de que $86 \%$ da população sobralense vive em zona urbana e apenas $14 \%$ na zona rural. O Município é politicamente dividido em 9 distritos: Aracatiaçu, A prazível, Bonfim, Caracará, J aíbaras, J ordão, Rafael Arruda, Taberuaba e Torto.

O solo apresenta boas condições químicas, mas o relevo, a pedregosidade, a pequena profundidade da cobertura sedimentar sobre rochas cristalinas, a susceptibilidade à erosão e evidências de desertificação, decorrência do manejo inadequado da terra, prejudicam a exploração econômica e o acesso dos que pretendem sobreviver da agricultura. A economia é sustentada pela produção agrícola, pecuária e um significativo movimento na indústria de transformação (vestuário, calçados, produtos alimentícios, minerais não metálicos e madeira) e comércio. A renda familiar tem a seguinte característica: $79 \%$ das famílias ganham até 2 salários mínimos e apenas $8 \%$ ganham de 5 a 20 salários mínimos.

A acelerada, mas desordenada urbanização, verificada nos últimos anos, tem agravado o problema habitacional no Município, provocando aglomeração, habitações inadequadas e surgimento de favelas. 
O sistema de abastecimento de água alcança $86 \%$ da população urbana. Já a rede elétrica, beneficia $97 \%$, enquanto as instalações sanitárias estão presentes em $71 \%$ das residências.

As ocupações dos chefes das famílias caracterizam-se por atividades ligadas à agricultura /pecuária, indústria e comércio e a maioria concentra-se no setor informal, evidenciando a pouca escolaridade da população. Quanto às possibilidades de trabalho e emprego, 2,7\% das pessoas dependem/vivem do trabalho de uma pessoa economicamente ativa (S obral, 1997).

TABELA 1 - A. E ELAAE . EE. A.

ALA..BALE 1.

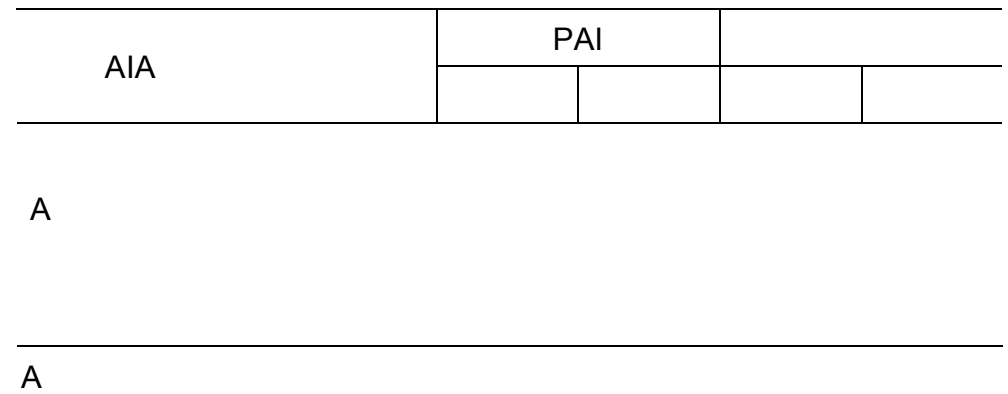

A escolaridade é muito baixa, refletindo diretamente nas oportunidades de trabalho e renda. Vale ressaltar, que o elevado percentual de $34 \%$ das famílias tem apenas a presença da mulher como chefe, $7 \%$ são dirigidas apenas pelo homem e $59 \%$ são chefiadas pelo casal. Nos últimos anos cresceu assustadoramente o número de mulheres abandonadas pelos maridos, tendo a mulher, muitas vezes, que assumir a responsabilidade da família sozinha. Em Sobral, este fato revela-se significativo, uma vez que a sobrevivência se torna mais complexa quando fica sob a liderança de apenas uma pessoa.

A maioria dessas famílias (74\%) sobrevive com até dois salários mínimos. É imprescindível destacaro fato de que destas, apenas $38 \%$ são assalariadas, e a grande parte ( $69 \%$ ) não tem uma renda fixa. Sobral ainda apresenta áreas de pobreza extrema, mas esta situação não distancia-se da realidade dos municípios brasileiros, particularmente da Região Nordeste. A situação econômica da maioria das famílias nordestinas não é diferente do cenário que encontramos em Sobral. São pessoas sobrevivendo com baixos salários, sendo que as necessidades básicas como moradia, alimentação, educação e lazer ficam a cada dia mais difíceis de satisfazer, pois o que ganham geralmente não cobre nem as despesas com alimentação.

Para Minayo (1992), no Brasil, as políticas sociais públicas (educação, saúde, habitação) têm, em geral, beneficiado mais os não-pobres do que os pobres, de modo que se faz necessário, com urgência, habilitar os pobres a uma inserção econômica e social que os liberte da situação de carência em que se encontram, principalmente pela educação básica e pela qualificação profissional.

A maior parte dos brasileiros, principalmente os nordestinos, apresentam uma grande taxa de analfabetismo, determinante que os exclui do mercado de trabalho e, de certa forma, de uma participação saudável em nossa sociedade. Nunca em toda a história os problemas sociais e econômicos tomaram dimensões tão prejudiciais, influenciando negativamente na saúde dos indivíduos, pois a percepção que se tem é de que os desgastes são maiores e aumentam significativamente os riscos de adoecer ou morrer da população pobre. A pobreza frustra o desejo e os sonhos das pessoas de construírem um futuro melhor, enquanto seu acesso limitado às estruturas políticas solapa as bases da sua auto determinação (Brasil, 1996).

No próximo tópico demonstraremos a opinião das famílias sobre a atuação do PSF no município de Sobral.

\section{A OPINIÃO DAS FAMÍLIAS SOBRE O PSF}

Os dados a seguir mostram a opinião das famílias sobre a atuação do PSF. Entendemos que não se pode construir serviços de qualidade sem a participação dos sujeitos do cuidado, sem a participação dos principais atores sociais, pois esta inclusão é um bom instrumento e talvez o melhor indicador para avaliação do 
funcionamento dos serviços de saúde. Não podemos, negar é claro, que existem outros tipos de instrumentos para se avaliar o impacto das ações sobre a saúde da população, mas a legitimidade dos serviços se dá de fato através da satisfação dos usuários. Com um processo de avaliação sistemático, poderemos estar de fato contribuindo para a participação e controle sociais.

O PSF é conhecido por $100 \%$ das famílias visitadas e todas as famílias referiram utilizar os serviços do Programa. Esta informação mostra que a atuação das equipes nos bairros não é desconhecida. A comunidade tem conhecimento de que em seu bairro existe uma equipe de profissionais de saúde responsável por seus cuidados. Sobre os profissionais que integram a equipe, $68 \%$ das famílias souberam descrever corretamente seus componentes, $23 \%$ não conseguiram identificá-los claramente e os outros $9 \%$ não se manifestaram.

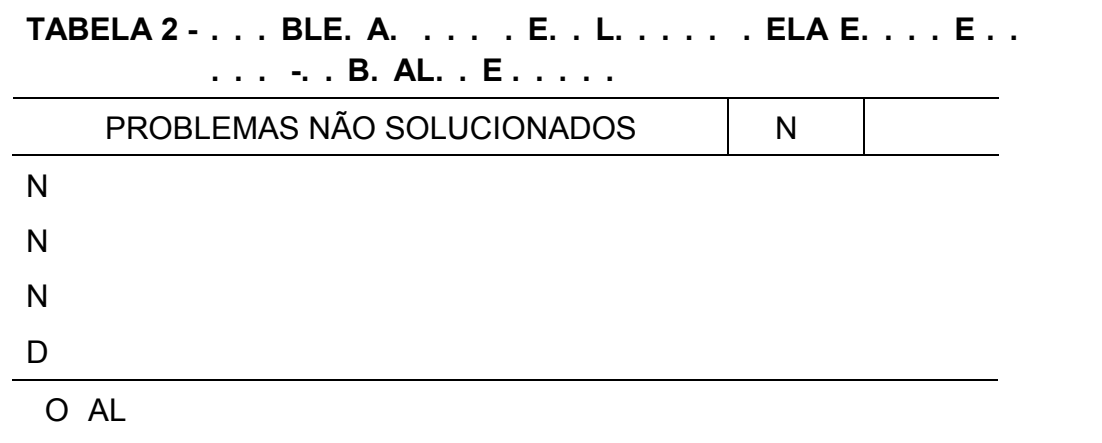

A resolução de problemas de saúde é um bom mecanismo para se verificar a eficiência dos serviços. Neste sentido, $73 \%$ das famílias tiveram todos os seus problemas solucionados, mas uma parcela de $18 \%$ refere falta do medicamento prescrito, $6 \%$ queixa-se de não ter sido atendida, e $3 \%$ alega que a diarréia em adulto não é solucionada na unidade.

Encontramos aspectos que retratam o modelo baseado na distribuição de remédio, pelo qual o cliente só acredita no serviço e no médico quando sai do posto com uma caixa de medicamentos. Mas também entendemos que ainda existem falhas na sua distribuição, principalmente porque ainda faltam os remédios da lista básica. Muitos clientes retornam para suas casas sem a aquisição do remédio, ou seja, sem solucionar seu problema, pelo menos sob a ótica deles. Existem dados de uma pesquisa realiza pela Fiocruz apud Ministério da Saúde (2000), que retratam os avanços obtidos pelo PSF e que podem reforçar os resultados encontrados, entre eles temos: maior acesso aos serviços de saúde; melhoria na qualidade do atendimento; aumento da satisfação do usuário; trabalho em equipe e territorialização do atendimento.

TABELA 3 - . . E . . . . A. . . A . . LA. TA. . . . . . -

. . B. AL. . E. . . .

\begin{tabular}{|c|c|c|}
\hline MELHORIAS & $\square \square \square$ & $\square$ \\
\hline 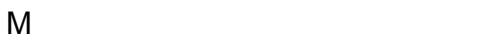 & $\square \square$ & $\square$ \\
\hline 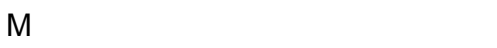 & & $\square$ \\
\hline 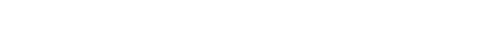 & $\square$ & $\square$ \\
\hline 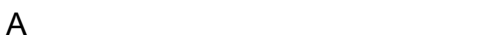 & $\square$ & ᄃ \\
\hline 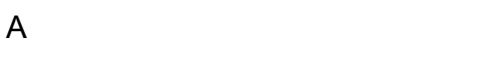 & & $\square$ \\
\hline 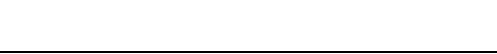 & & $\square$ \\
\hline$\square \mathrm{O} \square \mathrm{AL}$ & $\square \square$ & $\square \square \square$ \\
\hline
\end{tabular}

O PSF é de fato o acesso aos serviços de saúde de que a comunidade precisava, pois $68 \%$ das famílias referem que 0 acesso é a característica essencial do PSF. Parece ser unânime nas pesquisas já realizadas, 0 maior acesso dos indivíduos ao sistema de saúde. Este fato está diretamente relacionado com o princípio da adstrição, que pressupõe a responsabilidade de uma equipe de saúde ou profissionais por um determinado número de famílias, de base territorial definida, tendo em conta as contradições de vida mais ou menos homogêneas. 
O vínculo da equipe com a comunidade possibilita a execução do diagnóstico epidemiológico da população, para melhor resolver os problemas, e implementar ações com base em necessidades reais. Esse acesso e proximidade das famílias favorecem o envolvimento estreito com a comunidade e suas lideranças. O PSF poderá ser um instrumento de criação e de resgate da cidadania, já que a cidadania tem em sua base a ligação, que favorece resultados positivos para as partes envolvidas no processo relacional.

Os dados da pesquisa realizada pela Fiocruz apud Ministério da Saúde (2000), quando tratam dos avanços, mais uma vez mostram-se congruentes com os resultados deste estudo. 0 atendimento e tratamento domiciliar aparecem como positivos na opinião dos secretários de saúde. A melhoria na qualidade do atendimento também emergiu como indicativo de bom serviço prestado pelo PSF.

TABELA 4 . . . . . . . A. . A. . L. A. . B. E . . E . E. E

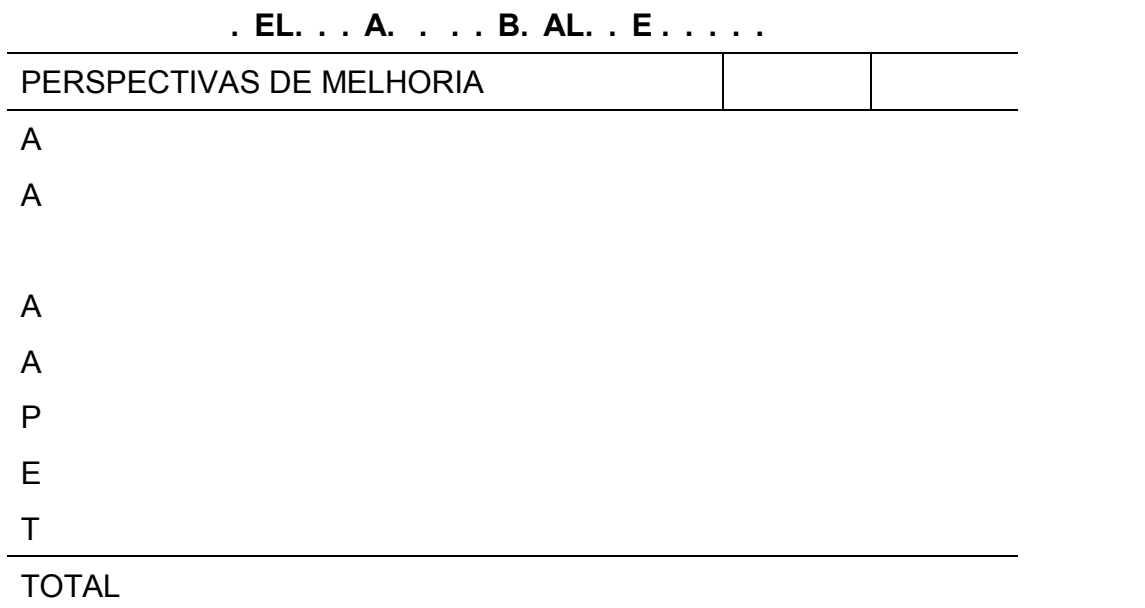

Os dados da tabela 4 mostram que as reivindicações de melhoria do serviço estão coerentes com as insatisfações já declaradas. A distribuição do medicamento surge como um problema na maioria das equipes (29\%). 0 atendimento também aparece com uma necessidade de melhoria, pois $21 \%$ das famílias, de maneira geral, não estão satisfeitas com o atendimento. Entre as solicitações mais freqüentes, tivemos: aumento do número de consultas médicas e mais rapidez nas consultas. Com relação às queixas, os entrevistados reclamaram da falta de gentileza e humanização e da falta de solução de alguns problemas.

Identificamos o desejo de maior número de visitas domiciliares, incluindo aqui as realizadas tanto pelos agentes de saúde, como pelos profissionais, médicos e enfermeiros. As famílias mostram que valorizam esta atividade e isso é uma informação interessante para os que atuam no programa, já que essa atividade é um elo importantíssimo entre as equipes e a comunidade. Para Mazza (1998), a visita domiciliar constitui uma atividade de assistência à saúde exercida junto ao indivíduo, à família e à comunidade. Seu objetivo é contribuir para a efetivação das premissas de promoção à saúde definidas pela Organização Mundial de Saúde e adotadas também pelo SUS no Brasil.

Ficou claro que as perspectivas de melhoria dos serviços estão nitidamente inseridas no modelo que prioriza igualitariamente a doença e o doente, com fundamento no conceito de saúde como ausência de doença e não como qualidade de vida. A valorização da atenção curativa e a falta de conscientização da importância da atenção primária podem justificar essa expectativa. Com tudo isso, não podemos perder de vista a qualidade da assistência que tem sido oferecida pelas equipes do PSF. Não podemos esquecer de que os princípios norteadores do PSF são a universalização da atenção, a eqüidade, a integralidade e a participação da comunidade.

Tanto as atividades desenvolvidas pelo PSF, como os problemas de saúde resolvidos pela equipe estão eminentemente relacionados com a área curativa. As dificuldades na inversão do paradigma que trata da doença e do doente é percebida no conjunto de atividades de que se ocupam as equipes, pois muitas ainda articulam seu trabalho à demanda espontânea. A queixa-consulta e as doenças são as atividades de destaque. Contudo, percebemos uma tímida atuação na área de promoção e de prevenção. No que concerne aos problemas resolvidos, as doenças agudas relacionadas com a miséria são a grande demanda nas unidades. 
A Secretaria de Saúde e Assistência Social de Sobral, ao realizar a I O ficina de Estratégias do Sistema Local de Saúde, em abril de 1997, com a participação de vários segmentos da comunidade, traçou a realidade objetiva do Município. Esta oficina foi um mecanismo importante para organização e construção do primeiro Plano Municipal de Saúde. Nesse documento, foram identificados alguns obstáculos, como: falta de compreensão dos conceitos fundamentais do modelo por parte dos profissionais e da própria população, o que dificulta um maior comprometimento com a sua construção; descrédito provocado pela não-continuidade de propostas anteriores; lógica de funcionamento direcionada pela produtividade e deficiência de recursos humanos (qualitativa e quantitativa); falta de participação e controle social, falta de integração dos profissionais e as diferentes ações realizadas (Sobral, 1997). Parece-nos que a maioria delas não foram extintas por completo. Algumas destas dificuldades, ainda latentes, podem contribuir para a demora da implantação efetiva do modelo assistencial.

O gerenciamento e organização do trabalho diário certamente é o melhor caminho para organizar a demanda espontânea, o que implicaria tempo disponível para realização de ações de caráter preventivo. Com isso, o PSF estará reordenando o modelo atual.

Verifica-se que somente desta forma, o PSF irá contribuir para a reorientação do modelo assistencial a partir da atenção básica, em conformidade com os princípios do Sistema Único de Saúde - SUS, imprimindo uma nova dinâmica de atuação nas unidades básicas de saúde, com definição de responsabilidades entre os serviços de saúde e a população (Brasil, 1998).

Q uando questionadas sobre os membros das equipes mais conhecidos, obteve-se o médico em primeiro lugar $(86 \%)$, os agentes de saúde em segundo (84\%) e os enfermeiros em terceiro (74\%). Neste caso, consideramos o papel histórico da figura do médico, pois a população faz questão de conhecer e dizer o nome do seu médico. No imaginário popular, o médico ainda aparece como um ser que salva vidas, que resgata a saúde e que tem um conhecimento ilimitado. Costa Neto (2000), lembra que está havendo uma busca pela adequação do médico à realidade social, pois historicamente este profissional esteve inserido em uma prática médica biológica, individualista e hospitalar, apresentando baixa cobertura e com elevado cus to, apesar de sua eficiência técnica nas respostas pontuais de procedimentos curativos individuais.

Com a implantação do PSF, o médico ficou mais próximo das famílias, comportamento que em outro momento histórico não acontecia, pois estes profissionais geralmente atendiam nos hospitais e grandes centros de saúde. A comunidade necessitará de tempo para perceber que outro modelo está sendo implantado, neste caso o médico continuará disponível prestando assistência a sua família sempre quer for preciso.

\begin{tabular}{|c|c|}
\hline OPINIÃO $\square \mathrm{O} \square \square \square \mathrm{O} \square \square \square \mathrm{N} \square \mathrm{I} \square \square \mathrm{N} \square \mathrm{O}$ & $\square$ \\
\hline प०० & $\square \square$ \\
\hline 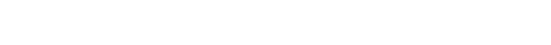 & $\square$ \\
\hline प्र०० & ૧० \\
\hline प्र००००० & $\square \square$ \\
\hline प्र० & $\square$ \\
\hline 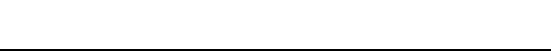 & $\square$ \\
\hline$\square \mathrm{O} \square \square$ & 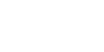 \\
\hline
\end{tabular}

A classificação bom, muito bom, ótimo, atingiu um soma de $78 \%$, sugerindo uma satisfação de maneira geral. É oportuno refletir sobre essa classificação e questionar os critérios que as famílias utilizaram para avaliar? Sabe-se que uma porção muito grande da população ainda se contenta com pouco, acredita que os gestores estão fazendo caridade, muitos têm dificuldades de reconhecer seus direitos, alguns nem têm noção das obrigações do Estado para com eles, desconhecem sua participação no incremento e geração dos impostos. Podemos encontrar indivíduos que acreditam que a assistência ofertada pelo Sistema Único de Saúde - SUS é obra de caridade dos governos. Campos (1991), faz uma reflexão oportuna: o pouco ou nenhum tempo de estudo relaciona-se com a ausência do conhecimento sobre a forma correta de assistência que deveria ser oferecida, facilitando assim, a aceitação de uma assistência que, muitas vezes, não é efetiva ou resolutiva. 
Acreditamos que os profissionais de saúde podem e devem atuar estimulando a cidadania, ou seja, abrindo um debate sobre a qualidade da atenção, sobre as dificuldades estruturais, particulares e singulares, resgatando e fortificando o raciocínio crítico da comunidade de maneira geral.

\section{CONCLUSÃO E CONSIDERAÇÕES FINAIS}

Todas as famílias deste estudo conhecem e utilizam os serviços prestados pelo PSF. O desejo de melhoria do programa emergiu principalmente nos seguintes aspectos: 0 aumento da oferta de medicamentos e 0 atendimento de maneira geral, caracterizando a assistência curativa que historicamente foi imposta aos brasileiros. Uma porcentagem significativa das famílias apontou como melhorias o acesso gratuito aos serviços de saúde, a redução das doenças e a qualidade nos atendimentos. As principais insatisfações são: falta de medicamentos, poucas consultas individuais e visitas domiciliares. A promoção da saúde aparece timidamente nas ações da equipe, refletindo a incapacidade das equipes em reverter imediatamente o modelo, que é movido pela lógica da demanda espontânea e assistência à doença. Ao classificar a atuação do PSF, a maioria avalia como ótimo, muito bom e bom.

Podemos chegar ao final deste trabalho afirmando que houve uma opinião satisfatória das famílias em relação à atuação das equipes do PSF no município, mas foi percebido também que os gestores municipais e profissionais de saúde estão diante de um grande desafio, a continuidade e melhoria das ações que os aproximam desta nova maneira de atenção à saúde, além, é claro, de empreender esforços para modificar as vulnerabilidades apontadas pelas famílias.

ABSTRACT: Descriptive exploratory study, occurred in Sobral city, located about $230 \mathrm{~km}$ from Fortaleza-C eará. The data collect period was from A pril to J une, 1999. We had as aim: to describe the perception of the families/ community about the work of the family health program in city. We choose 13 health unit from the urban zone. In this area was interviewed 123 families, through the families visits, by 43 students from the first period of the Nursing Course. The results showed that $100 \%$ of the family know and use services from the program, $73 \%$ had their problems solved by the team, $68 \%$ refers that the access to the health service was improved. The opinions about what should get better, most families still wishing an attendance based on cure field, this shows that the improvement perspective of the services are base on the assistential model that existed for many years.

KEY WORDS: Family health; Health plans and programmes; Evaluation; Community development.

RESUMEN: El objetivo del seguiente trabajo es discribir la percepción de las famílias/ comunidad sobre la actuacion del PSF ( P rograma salud de la família) en el municipio de Sobral. F ueram escogidas 13 unidades de salud de la zona urbana. En estas localidades fueran 123 famílias que recebieram la visita de 43 estudiantes de enfermeria. Los resultados demonstran que $100 \%$ de las famílias conocen e hacen uso del PSF, de estos $73 \%$ tuvieron sus problemas resultos por las equipes de salud, $68 \%$ referen esos serviços han melhojorado. A respeto de lo que deve mejorar la gran mayoria de la población desea atención curativa que há dominado por ãnos nuestra sociedade.

PALABRAS CLAVES: Salud de la Família; Planos y programas de la salud; Evaluacion; Desarrollo de la comunidad.

\section{REFERÊNCIAS BIBLIOGRÁFICAS}

1. BRASIL. Ministério da Saúde. Normas para pesquisa envolvendo seres humanos: Res. Conselho Nacional de Saúde 196/96 e outras. Brasília, 2000.

2. _._. Ministério da Saúde. O Brasil abre as portas para a saúde entrar. Revista Brasileira de Saúde da Família, n.2, junho/julho, Brasília. 2000.

3. __-_. Ministério da Saúde. Programa Saúde da Família: residência multiprofissional em saúde da família. Brasília, 1999.

4. _._. Ministério da Saúde. Promoção da Saúde : Carta de Ottawa, Declaração de Adelade, Declaração de Sundsvall, Declaração de Bogotá. Brasília, 1996. 

Ministério da Saúde. Saúde da família: uma estratégia para a reorientação do modelo assistencial. Brasília, 1998.

6. CAMPOS, G. W. S. Reforma da reforma: repensando a saúde. São Paulo: Hucitec, 1991.

7. COSTA NETO, M.M. O currículo médico e o sistema de saúde em construção. In: Revista Brasileira de Saúde da Família. Brasília, n.2, p , jun./jul. 2000.

8. DOMING UEZ, B. N. R. O Programa Saúde da Família: como fazer. Belo Horizonte, 1998.

9. MAZZA, M.M.P.R. A visita domiciliar como instrumento de assistência de saúde. R io de J aneiro : Faculdade de $S$ aúde Pública, 1998.

10. MINAYO, M.C.S. (Org.). A saúde em estado de choque. R io de J aneiro : Espaço e Tempo/Fase, 1992.

11. MIRANDA, A. S. Programa Saúde da Família: entre a panacéia e o preconceito. F ortaleza, 1998, Mimeografado.

12. SOBR AL. Prefeitura Municipal. Plano Municipal de Saúde. Sobral, 1997.

\section{ANEXO}

\section{FORMULÁRIO APLICADO NAS FAMÍLIAS}

\section{1- Condições da moradia}

Quantos cômodos ( ..) Alugado ( ) Próprio ( ) ( ) Outros

Quantas pessoas residem ( ) Crianças ( ) Adolescentes ( )Adultos ( ) Idosos ( )

Escolaridade do Chefe da família- Pai ( ) Mãe ( )

Renda familiar - em salários mínimos ( )

2 - A família conhece o Programa Saúde da Família - PSF ?

$\operatorname{Sim}($ ) Não ( )

3 - A família já utilizou os serviços do PSF? Sim ( ) Não ( )

4 - Quais os profissionais que trabalham nas equipes do PSF ?

5 - Quais os problemas de saúde que o PSF não conseguiu resolver?

6 - Quais as mudanças que ocorreram após a implantação do PSF em seu bairro ?

7 - 0 que deve melhorar no atendimento das equipes do PSF?

8 - Qual o profissional da equipe do PSF é o mais conhecido da família?

9 - Quais as atividades do PSF a família considera satisfatórias?

10 - Como a família classificaria/conceituaria a atuação do PSF em seu bairro?

Ruim ( ) Regular ( ) Bom ( ) Muito Bom ( ) Ótimo ( ) Excelente ( ) 